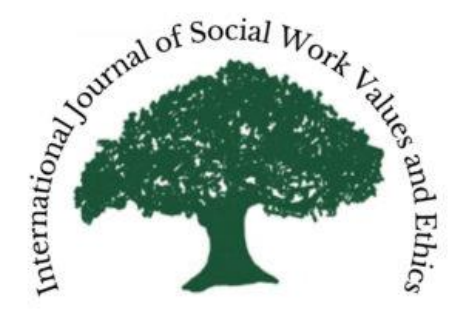

International Journal of Social Work Values and Ethics

Volume 19, Number 1 (2022)

ISSN: 2790-6345

DOl: 10.55521/10-019-100

www.jswve.org 


\section{Changes at IJSWVE and Thank You}

\section{DOl: 10.55521/10-019-105}

Stephen M. Marson, Editor, and Laura Gibson, Book Review Editor

\section{International Journal of Social Work Values and Ethics • Volume 19(1), Copyright 2022 by IFSW}

This text may be freely shared among individuals, but it may not be republished in any medium without express written consent from the authors and advance notification of IFSW.

We have an addition to our Editorial and Policy Boards. We haven't had a student member for about fiveyears. I have been able to recruit an excellent addition. Rachel (Ray) Mathew-Santhosham is an BSW/MSW Candidate with The Ohio State University. Her family is from India. Bettina Leibetseder, Dr. rer. soc. oec. was recruited to our editorial board because of her background in macro practice, research, and statistics. Currently, she holds a professorship at University of Applied Sciences Landshut in Germany. Jörgen Lundälv, Ph.D. also is joining our editorial board. He is an Associate Professor of Social Work from the University of Cothenburg in Sweden. He specializes in disability studies. We are fortunate to successfully recruit three new members of our Policy Board. Hassan Mousavi Chelak, Ph.D. is the President of Iran Association of Social Workers. Jane Shears, ProfDoc is the Head of Professional Development and Education at British Association of Social Workers. Céline Lembert, MS joins our board to represent France. She is employed by the Public Mental Health Facility in Paris and is a member the Ethics and Deontological Commission of the High Labor Council.

A great deal of work goes into each issue of the International Journal of Social Work Values and Ethics. All work on our journal is completed by volunteers and no one - including our publisher IFSW - makes a financial profit from the publication. In addition, we have unsung heroes on our editorial board 
who contribute to the existence of our journal. Because we have a rule that requires our manuscripts to be assessed anonymously, I cannot offer public recognition of their names. I thank them! However, I can publicly announce the names of our hard-working copy editors. Their work is not confidential. For their major contributions to this issue, I must publicly thank:

- Alison MacDonald

- $\quad$ Eric M. Levine

- Amelia Chesley

- Jan Summerson

- Donna DeAngelis

- Kathleen Hoffman

I also thank the book reviewers for the generous gift of their time to read and write thoughtful reviews:

- MaryAnn Thrush, PhD, MSW

- J. Porter Lillis, Ph.D. 